\title{
Modeling of Casting Microstructures and Defects
}

\author{
A. B. Shapiro \\ L. T. Summers \\ D. J. Eckels \\ V. Sahai
}

September 26, 1997

This is an informal report intended primarily for internal or limited external distribution. The opinions and conclusions stated are those of the author and may or may not be those of the Laboratory.

Work performed under the auspices of the U.S. Department of Energy by the Lawrence Livermore National Laboratory under Contract W-7405-Eng-48. 


\section{DISCLAIMER}

This document was prepared as an account of work sponsored by an agency of the United States Government. Neither the United States Government nor the University of California nor any of their employees, makes any warranty, express or implied, or assumes any legal liability or responsibility for the accuracy, completeness, or usefulness of any information, apparatus, product, or process disclosed, or represents that its use would not infinge privately owned rights. Reference herein to any specific commercial product, process, or service by trade name, trademark, mamufacturer, or otherwise, does not necesearily constitute or imply its endorsement, recommendation, or favoring by the United States Government or the University of California. The views and opinions of authors expressed herein do not necessarily state or reflect those of the United States Government or the University of California, and shall not be used for advertising or product endorsement purposes.

This report has been reproduced directly from the best available copy.

Available to DOE and DOE contractors from the Office of Scientific and Technical Information

P.O. Box 62, Oak Ridge, TN 37831

Prices available from (615) 576-8401, FTS 626-8401

Available to the public from the

National Technical Information Service

U.S. Department of Commerce

5285 Port Royal Rd.,

Springfield, VA 22161 


\title{
Modeling of Casting Microstructures and Defects
}

\author{
A.B. Shapiro, L.T. Summers, D.J. Eckels, V. Sahai
}

This project was supported by Lawrence Livermore National Laboratory LDRD/ERD funding, project 97-ERD-073. This report describes the work done on this project during FY97. Contributors to this project were:

1. Art Shapiro (ME/NTED) - project leader, theoretical developments and experiment design

2. Leonard Summers (C\&MS) - Appendix 2: Physical Properties of Solid and Liquid Uranium

3. Del Eckels (ME/NTED) - experiment fabrication and execution

4. Vivek Sahai (ME/NTED) - GLO code optimization calculations

\section{Introduction}

Our interest in casting is linked to DOE efforts to reduce hazardous waste and scrap produced by metal component fabrication processes. Improved processes for manufacturing plutonium and uranium components, for example, can minimize scrap metal, contaminated waste, and possible radiation exposure, and reduce the cost of equipment and facilities.

Casting is an ancient art that has been a trial-and-error process for more than 4000 years. To predict the size, shape, and quality of a cast product, casting manufacturers typically cast full-size prototypes. If one part of the process is done incorrectly, the entire process is repeated until an acceptable product is achieved.

One way to reduce the time, cost, and waste associated with casting is to use computer modeling to predict not only the quality of a product on the macro-scale, such as distortion and part shape, but also on the micro-scale such as grain defects. Modeling of solidification is becoming increasingly feasible with the advent of parallel computers. There are essentially two approaches to solidification modeling. The first is that of macro-modeling where heat transfer codes model latent heat release during solidification as a constant and based solely on the local temperature. This approach is useful in predicting large scale distortion and final part shape. The second approach, micro-modeling, is more fundamental. The micro-models estimate the latent heat release during solidification using nucleation and grain growth kinetics. Micro-models give insight into cast grain morphology and show promise in the future to predict engineering properties such as tensile strength.

The micro-model solidification kinetics can be evaluated using first principles or they can be evaluated using experiments. This work describes an implementation of a micro-model for uranium which uses experimental results to estimate nucleation and growth kinetics.

\section{Mathematical Formulation}

The primary and most obvious phenomenon controlling casting is the transfer of heat from the cooling metal to the mold and surroundings. The present needs of many foundries are being satisfied by relatively simple heat conduction modeling that merely indicate regions of risk for shrinkage porosity. Coupled with empirical experience, foundry engineers 
successfully cast parts used in life critical applications (e.g., jet engine turbine components [1]). However, DOE's vision is to move from empiricism to science based design.

Table 1: Equation symbols and values used in the solution of equations 2,3 and 5.

\begin{tabular}{|c|c|c|}
\hline $\begin{array}{l}\text { A } \\
\text { C } \\
\text { h } \\
\text { L } \\
\text { N } \\
\text { R } \\
\text { T }\end{array}$ & $\begin{array}{l}\text { area } \\
\text { heat capacity } \\
\text { convection heat transfer coefficient } \\
\text { latent heat } \\
\text { number of nucleation sites } \\
\text { grain radius } \\
\text { temperature }\end{array}$ & $\begin{array}{l}6.0 \mathrm{e}-04 \mathrm{~m}^{2} \\
920 . \mathrm{J} / \mathrm{kg} \mathrm{C} \\
2 . \mathrm{W} / \mathrm{m}^{2} \mathrm{C} \\
4.44 \mathrm{e}+05 \mathrm{~J} / \mathrm{kg} \\
1.0 \mathrm{e}+06 \mathrm{grains} / \mathrm{m}^{3}\end{array}$ \\
\hline $\begin{array}{l}t \\
V \\
V\end{array}$ & $\begin{array}{l}\text { environment temperature } \\
\text { phase change temperature } \\
\text { time } \\
\text { volume } \\
\text { solid volume fraction } \\
\text { nucleation rate law constant }\end{array}$ & $\begin{array}{l}25 . \mathrm{C} \\
660 . \mathrm{C} \\
1.0 \mathrm{e}-06 \mathrm{~m}^{3}\end{array}$ \\
\hline$\rho$ & density & $2698 . \mathrm{kg} / \mathrm{m}^{3}$ \\
\hline$\mu$ & grain growth law constant & $3.0 \mathrm{e}-06 \mathrm{~m} / \mathrm{s} \mathrm{C}^{2}$ \\
\hline
\end{tabular}

Heat conduction analysis codes model latent heat release during solidification as a constant and based solely on the local temperature. The next step in solidification modeling is to make the latent heat a function of the solidification fraction which depends on the nucleation rate and a grain growth rate. Equation 1 is an energy balance on a small volume of liquid which equates the change in internal energy to heat lost by convection to the environment plus generation of latent heat during phase change.

$$
\rho c \frac{d T}{d t}=-h \frac{A}{V}\left(T-T_{\infty}\right)+\rho L \frac{d V_{s}}{d t}
$$

Equation 1 can be re-arranged to give the rate of change of temperature for the control volume.

$$
\frac{d T}{d t}=-\frac{h}{\rho c} \frac{A}{V}\left(T-T_{-\infty}\right)+\frac{L}{c} \frac{d V_{s}}{d t}
$$

The first term on the right-hand side of equation 2 reflects the effect of casting geometry (ratio of the surface area of the casting to its volume) upon the extraction of sensible heat, while the second term takes account of the continuing evolution of latent heat of fusion during solidification. It can be seen from this equation that during solidification, heating will occur if the second term on the right-hand side of equation 2 becomes greater than the first one. This is known as recalescence and is shown graphically in figure 1.

The evolution of solid $\left(\mathrm{V}_{\mathrm{g}}\right)$ depends on the number of nucleation sites $(\mathrm{N})$ and a grain growth rate (dR/dt). 


$$
\frac{d V_{s}}{d t}=N 4 \pi R^{2} \frac{d R}{d t}\left(1-V_{s}\right)
$$

Micro-models estimate the evolution of solid during solidification using nucleation and growth kinetics. Several kinetic rate equations have been reported in the literature [2]. Two different models can be used for the nucleation law: continuous nucleation or instantaneous nucleation. An example of a continuous nucleation rate law is

$$
\frac{d N}{d t}=\beta\left(T_{l}-T\right) \frac{d T}{d t}
$$

For an instantaneous nucleation model, the number of grains per unit volume, $\mathrm{N}$, is determined by counting the number of grains in a micrograph of the casting.

An undercooling dependent equation was used to estimate the growth rate.

$$
\frac{d R}{d t}=\mu\left(T_{t}-T\right)^{2}
$$

Equations 2, 3 and 5 form a system of ordinary differential equations which can be solved numerically for the temperature, solid fraction, and grain radius as a function of time. The FORTRAN code is contained in Appendix 1. Figure 1 shows the temperature response for a hypothetical material with properties defined in Table 1 . Notice the phenomena of recalescence occurring at a time of 50 seconds.

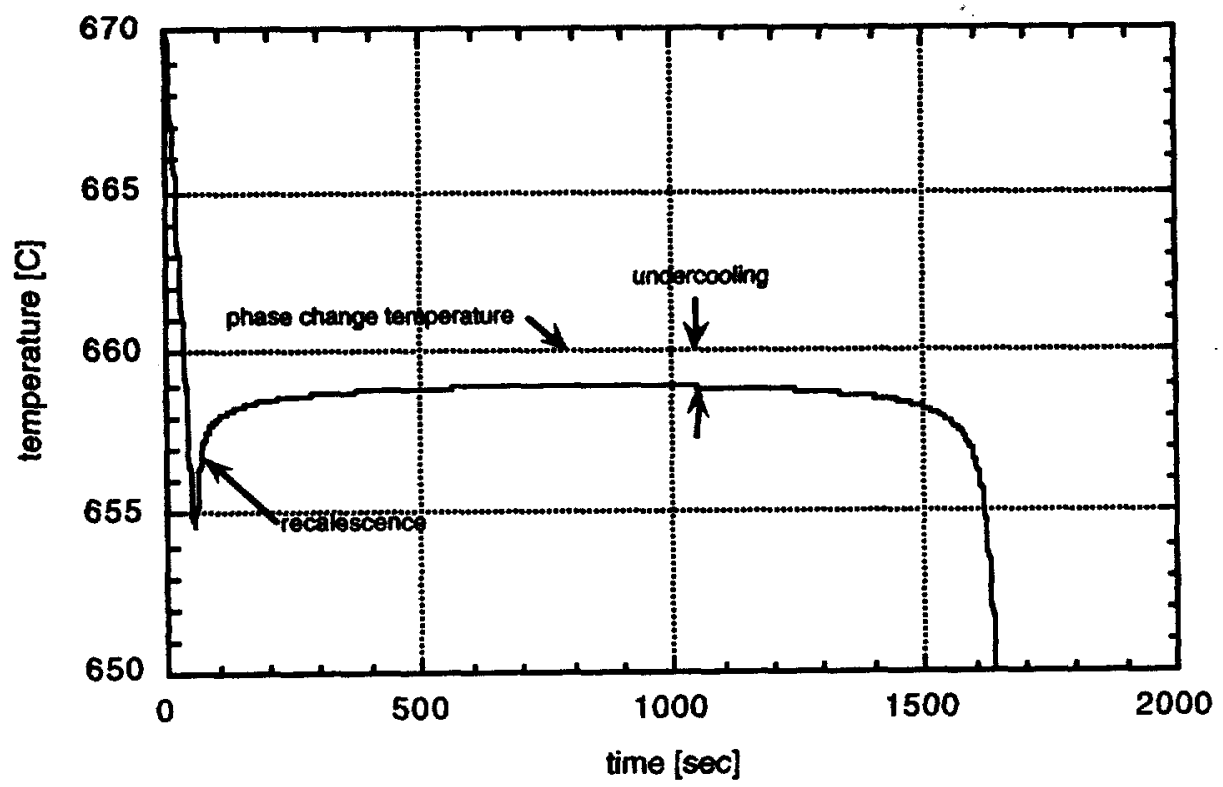

Figure 1: The solidification curve shown is the temperature solution from solving equations 2,3 and 5 using the variables defined in Table 1 . Notice the prediction of recalescence at time $=50$. 


\section{Obtaining Rate Constants From Experimental Data}

The evaluation of the kinetic laws based on first principles are just in the formative stages and are a current research area. An alternate approach is to evaluate the rate constants from experimental results on a simple casting, and then apply the laws to a production casting model. This can be accomplished by recording temperature versus time data from a solidification experiment and then using an optimization method to calculate the grain growth constant, $\mu$, by minimizing the difference between the experimental data and the temperature response calculated by equations 2,3 , and 5 .

The Global Local Optimization code (GLO) [3] was used. GLO is a macro-program controller which runs other programs under an optimization method. GLO uses a Broyden, Fletcher, Goldfarb, and Shanno variable metric sequential quadratic programming methodology with a modified Powell merit function. GLO treats the slaved program as an objective function, supplying it with new parameter values for optimization. The figure of merit (FOM) to be minimized is defined as the squared error difference between the experimental result and the calculated result. GLO runs the optimization modules in a loop until it finds the best set of parameters by minimizing the FOM.

To validate the approach, the data in figure 1 was used to represent experimental data and GLO was used to calculate the grain growth constant. This provides a method to evaluate the robustness of GLO by comparing the optimized prediction of the grain growth constant to the value used to create the curve in figure 1 (i.e., $\mu=3.0 \mathrm{e}-06 \mathrm{~m} / \mathrm{s} \mathrm{C}^{2}$ ).

Some of the important variables in the optimization procedure include the selection of the initial guess, and the upper and lower bounds of the variable to be optimized. Table 2 summarizes the results from variations in these parameters. This table gives the values of the figure of merit and percentage error based on the comparison with the known value of $\mu$. From the table, it can be seen that the values of the initial guess and for the upper and lower bounds are very important factors which affect the optimized variable result. From the behavior, it was determined that initial guesses between 500e-6 and 10.e-6 can yield good results. It was hard for the optimization code to obtain the correct value of the coefficient when a initial guess was given below the correct value. The upper bound values are more important in determining the optimized growth kinetic coefficient than the lower bound values as shown in the variation of lower bound parameters at a initial value of $500 \mathrm{E}-6$. Based on the trends shown by the table, it is recommended that for an actual situation where the growth coefficient is unknown a series of optimizations be performed to

\begin{tabular}{|llllll|}
\hline \multicolumn{6}{l}{ Table 2: GLO optimization code results in predicting $\mu=3.0 \mathrm{e}-06$} \\
initial guess & upper bound & lower bound & prediction & \multicolumn{1}{l|}{ figure of merit \% erro } \\
& & & & & \\
$500 \mathrm{e}-06$ & $1100 \mathrm{e}-06$ & $0.01 \mathrm{e}-06$ & $3.22 \mathrm{e}-06$ & 2.67 & 7.33 \\
$500 \mathrm{e}-06$ & $1100 \mathrm{e}-06$ & $0.1 \mathrm{e}-06$ & $2.9978 \mathrm{e}-06$ & $1.6 \mathrm{E}-3$ & 0.07 \\
$500 \mathrm{e}-06$ & $1100 \mathrm{e}-06$ & $1.0 \mathrm{e}-06$ & $2.98796 \mathrm{e}-06$ & $2.4 \mathrm{E}-2$ & 0.40 \\
$100 \mathrm{e}-06$ & $200 \mathrm{e}-06$ & $0.01 \mathrm{e}-06$ & $2.9675 \mathrm{e}-06$ & $8.2 \mathrm{E}-2$ & 1.08 \\
$10 \mathrm{e}-06$ & $100 \mathrm{e}-06$ & $0.01 \mathrm{e}-06$ & $2.9997 \mathrm{e}-06$ & $5.2 \mathrm{E}-3$ & 0.01 \\
$1 \mathrm{e}-06$ & $100 \mathrm{e}-06$ & $0.01 \mathrm{e}-06$ & $10.684 \mathrm{e}-06$ & 481.94 & 256 \\
$1 \mathrm{e}-06$ & $10 \mathrm{e}-06$ & $0.01 \mathrm{e}-06$ & $3.000 \mathrm{e}-06$ & 0.000 & 0 \\
$0.1 \mathrm{e}-06$ & $100 \mathrm{e}-06$ & $0.01 \mathrm{e}-06$ & $10.099 \mathrm{e}-06$ & 451.4 & 237 \\
$0.05 \mathrm{e}-06$ & $100 \mathrm{e}-06$ & $0.01 \mathrm{e}-06$ & $10.049 \mathrm{e}-06$ & 448.8 & 235
\end{tabular}


determine the effect of these parameters. The best initial set of values to use would be $500 \mathrm{e}-$ 6 as the initial guess, $1100 \mathrm{e}-6$ as the upper bound and $0.1 \mathrm{e}-6$ as the lower bound.

\section{Experimental Design}

A schematic of the experimental apparatus is shown in Figure 3. The size of the crucible and insulation was designed by numerical modeling to produce axial solidification. The finite element mesh is shown in Figure 4 and temperature contours during the solidification are shown in Figure 5. Notice the horizontal shape of the contours at the bottom of the crucible where we are trying to produce axial solidification between the 2 thermocouple positions as indicated in Figure 3 . The initial condition for all materials in the model was set to $1673 \mathrm{~K}$. Convection and radiation boundary conditions were specified on all exterior surfaces with a convection heat transfer coefficient of $5 \mathrm{~W} / \mathrm{m}^{2} \mathrm{C}$, an ambient temperature of 298K, and a surface emissivity of 0.8 .

The apparatus shown in Figure 3 was fabricated and instrumented. A data acquisition system was assembled using a PC and add-on analog cards for thermocouple sensors. A cylindrical furnace and power supply were obtained from a previous LLNL experiment. We validated the experimental procedure using aluminum. The recorded temperature data for the top thermocouple in the sample is shown in Figure 2. However, we were unable to field the experiment using uranium before the closure of this 1 year project. The problem was scheduling time in a glove box for protection against radiation exposure.

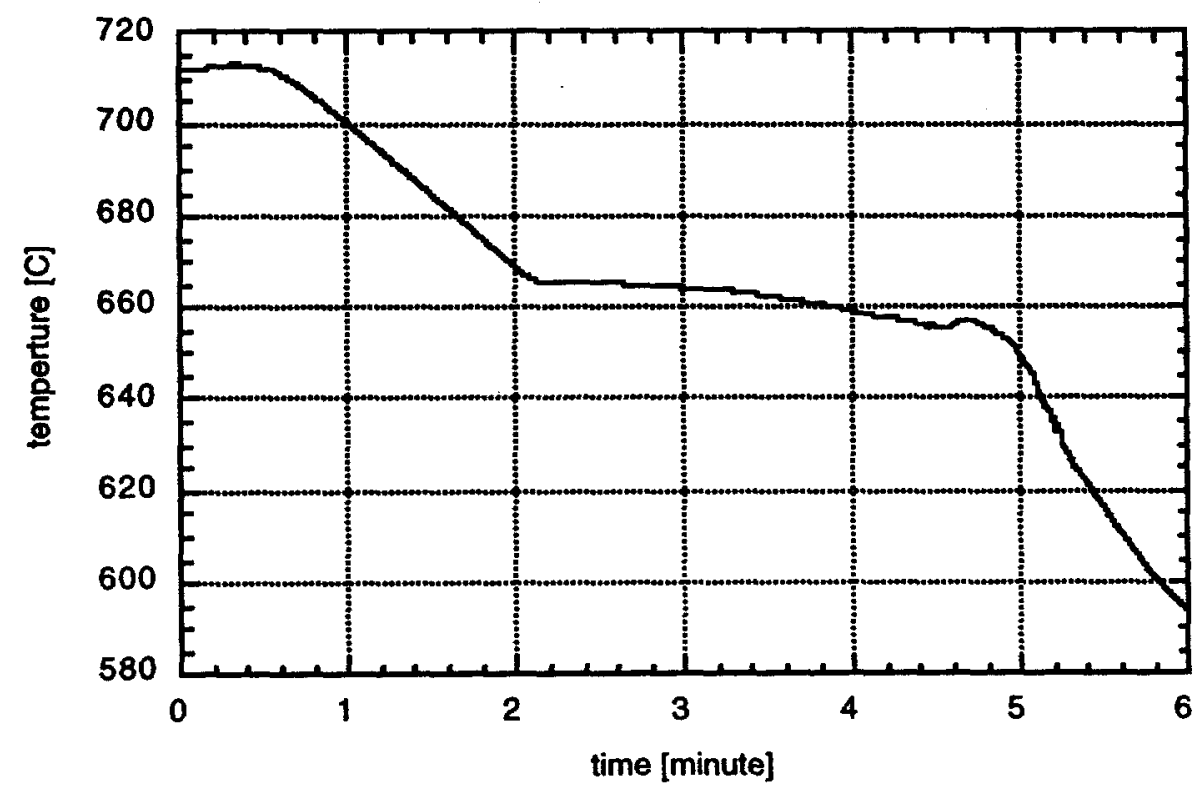

Figure 2: Shown is the temperature history recorded by the top thermocouple in figure 2 for aluminum solidification in the crucible. 


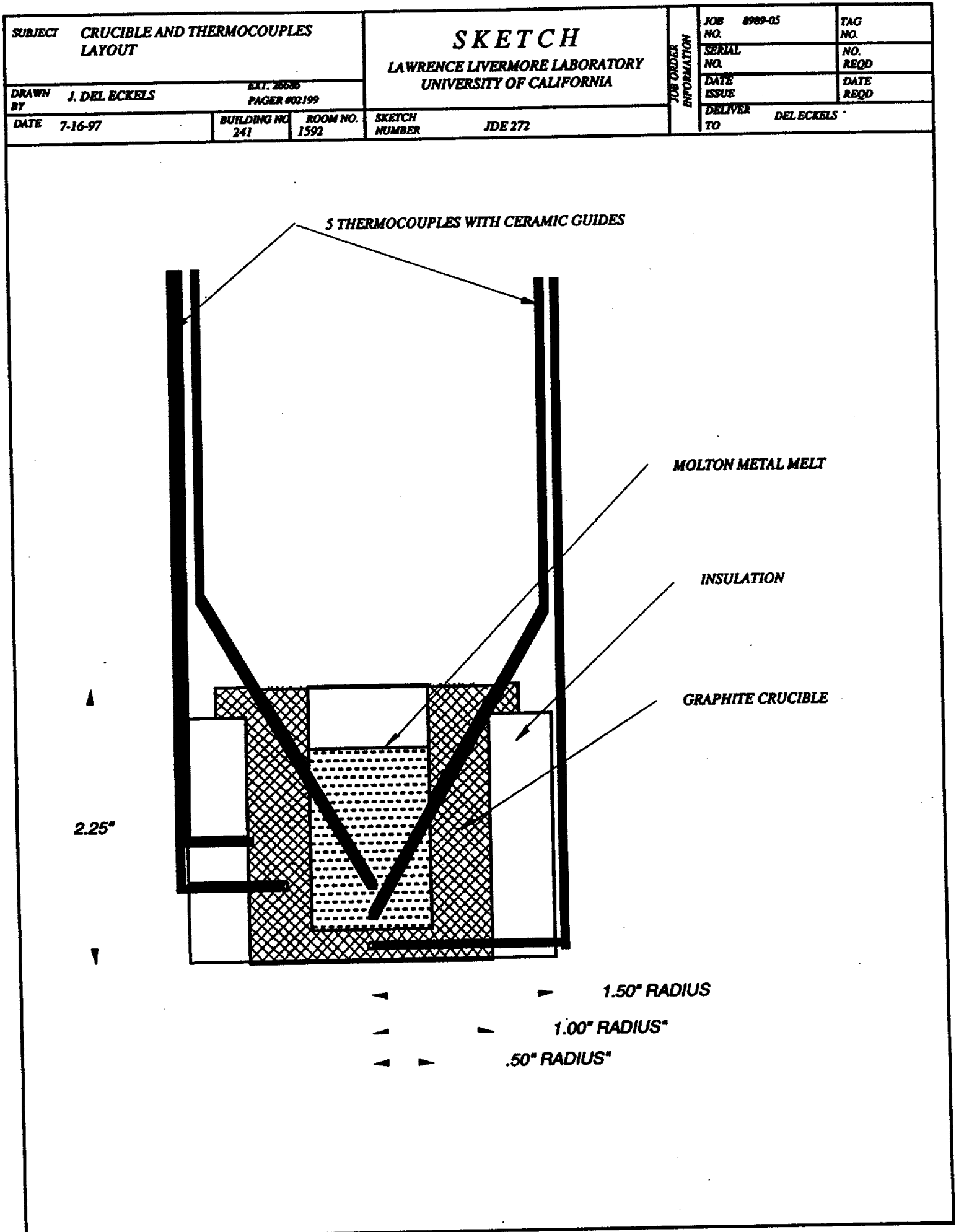

Figure 3: Shown is a schematic of the experimental apparatus. The apparatus was designed using numerical modeling to produce 1-dimensional axial solidification as shown in Figure 5. 


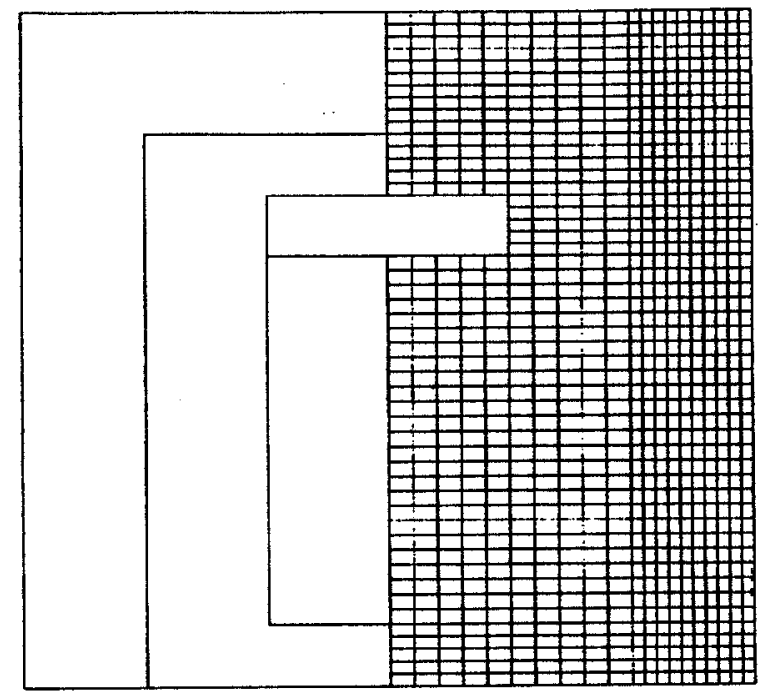

Figure 4: Shown is the finite element mesh used in the numerical model of the experiment.

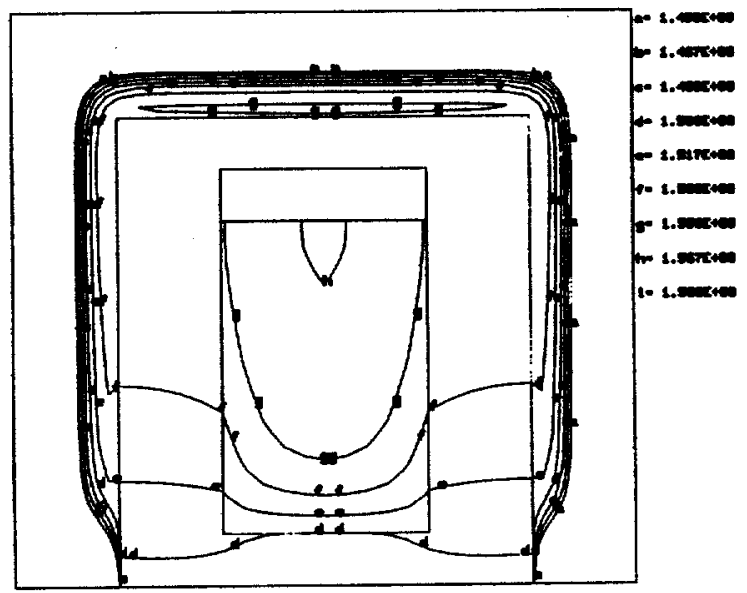

Figure 5. Shown are temperature $[\mathrm{K}]$ contours during solidification of the uranium. Notice the horizontal shape of the contours at the bottom of the crucible where we are trying to produce axial solidification between the 2 thermocouple positions as indicated in Figure 3. 


\section{References}

1. John S. Tu and R. Kelly Foran, "The Application of Defect Maps in the Process Modeling of Single Crystal Investment Casting," Journal of Metals, June 1992, pp 26-28.

2. D. M. Stefanescu et al., "Modeling the Evolution of Equiaxed Microstructure in Castings," Journal of Metals, February 1989, pp 22-25.

3. M. J. Murphy et al., "GLO User's Manual," University of California, Lawrence Livermore National Laboratory. 
Appendix 1: FORTRAN code solving equations 2, 3 and 5 using the variables defined in Table 1.

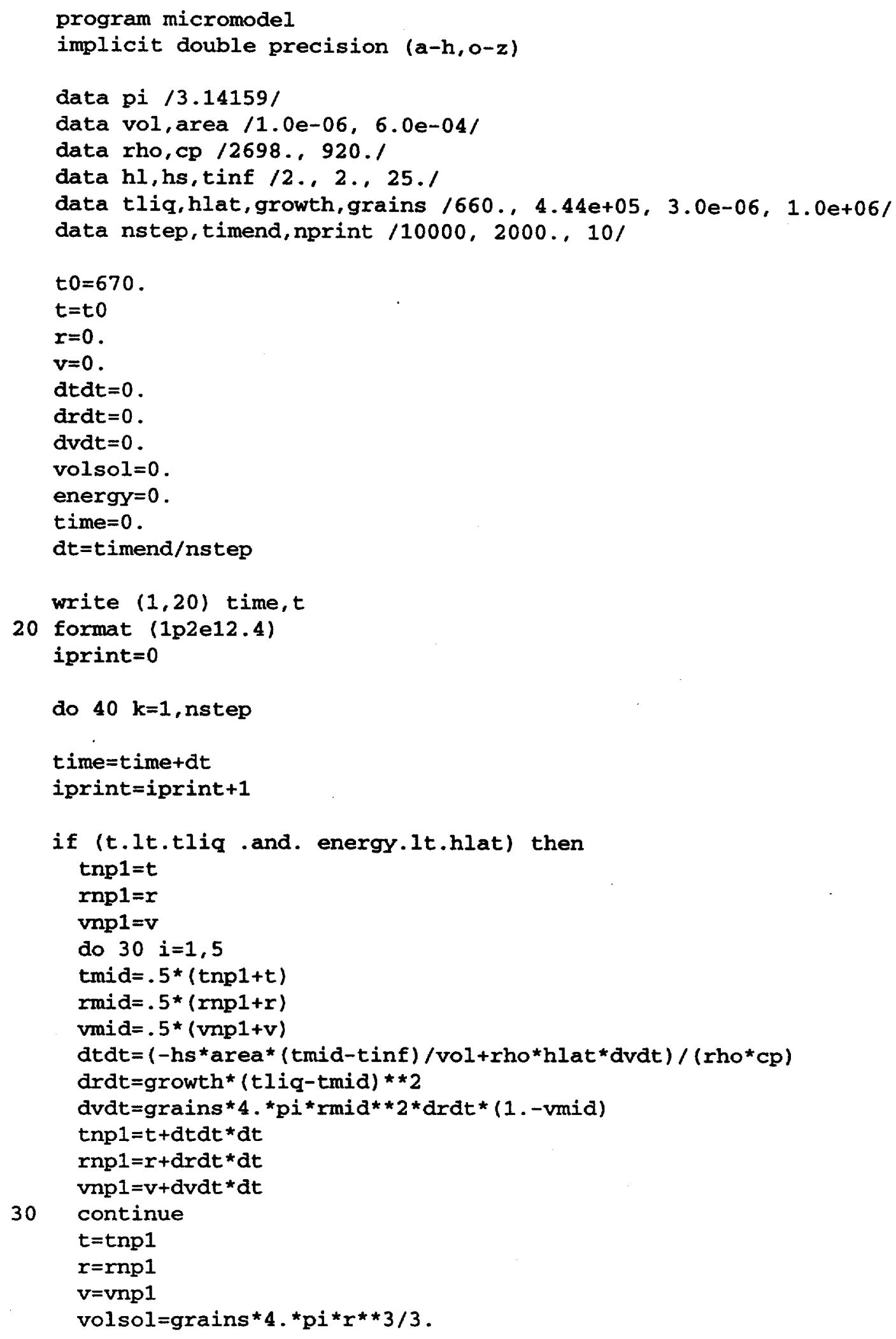




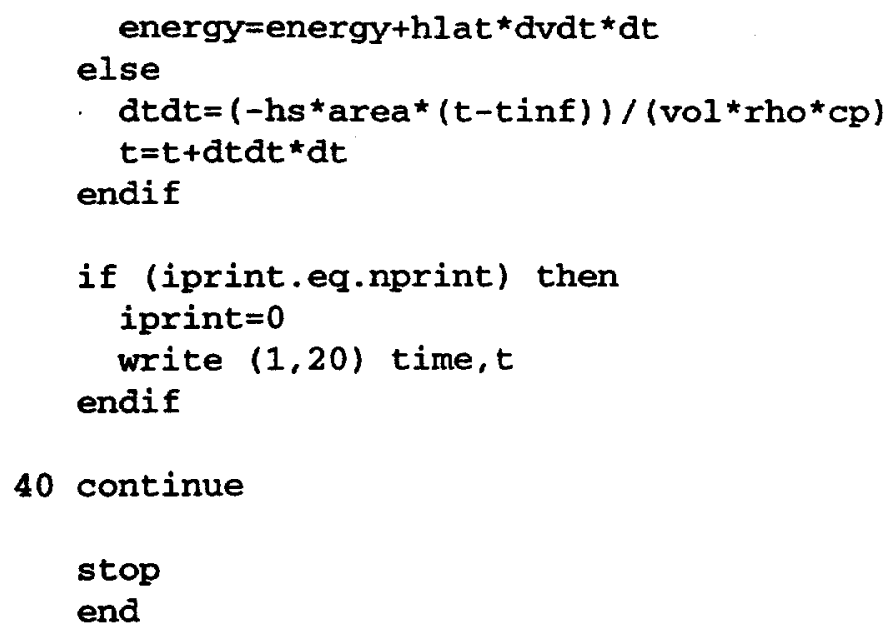




\section{Appendix 2. Physical Properties of Liquid and Solid Uranium (by Leonard}

T. Summers)

\section{Introduction}

This represents a partial list of the physical properties of liquid and solid uranium as a function of temperature. These data are intended only for the use in the LDRD funded effort to model casting microstructures and defects.

\section{Density}

\section{Liquid Phase}

There is a wide spread in the uranium liquid phase densities reported in the literature. A sampling of reported data is shown in Table 1 . Drotning (SANL), using the gamma ray absorption technique, reports a density of $16.95 \mathrm{~g} \mathrm{~cm}^{-3}$ at the liquidus with a temperature dependence of $1.29 \times 10^{-4} \mathrm{~g} \mathrm{~cm}^{-3} \mathrm{~K}^{-1}$. 1 Shaner, from LLNL, reports values of $17.6 \mathrm{~g}$ $\mathrm{cm}^{-3}$ and $1.74 \times 10^{-3} \mathrm{~g} \mathrm{~cm}^{-3} \mathrm{~K}^{-1}$ as measured using isobaric expansion experiments (IEX). ${ }^{2}$ Grosse et al. also measured the density of liquid uranium using the Archimedean technique. ${ }^{3}$ The Drotning data represents the lower bound for density measurements of liquid U while those of Grosse et al. are near the high side of reported values.

Table 1. Reported densities of molten uranium

\begin{tabular}{c|c|c}
\hline Researcher & $\begin{array}{c}\text { Density } \\
\text { (at melting point) } \\
\mathrm{g} \mathrm{cm}^{-3}\end{array}$ & $\begin{array}{c}\text { Temperature dependence } \\
\mathrm{g} \mathrm{cm}^{-3} \mathrm{~K}^{-1}\end{array}$ \\
\hline Drotning & 16.95 & $1.29 \times 10^{-4}$ \\
Shaner & 17.6 & $1.74 \times 10^{-3}$ \\
Grosse & 17.9 & $1.05 \times 10^{-3}$ \\
Steinberg & 17.27 & $1.03 \times 10^{-3}$ \\
\hline
\end{tabular}

Iida and Guthrie reference the survey work of Steinberg wherein he considered the ranges of temperature over which experimenters measured the density and the anticipated accuracy for the types methods they employed. ${ }^{4}$ Steinberg's recommended values (as reported by lida and Guthrie) are $17.27 \mathrm{~g} \mathrm{~cm}^{-3}$ with a temperature dependence of $1.03 \times 10^{-3}$ $\mathrm{g} \mathrm{cm}^{3} \mathrm{~K}^{-1}$. I recommend that the Steinberg values be employed as they are derived from several sources which are critically analyzed for accuracy. Note, however, that no temperature range of applicability has been specified for the Steinberg data. 4 


\section{Solid Phase}

The density (as well as thermal expansion) of solid uranium is complicated by several issues. First there are 3 allotropic phases between room temperature and the melting point. Secondly, within each allotrope there exists a crystallographic anisotropy of some properties. Thirdly, properties such as density, are influenced by the soundness of castings.

The density and lattice constants of solid uranium as a function of temperature have been surveyed by Gittus and are shown in Table 2.5 The data are from several sources and should be considered to be reasonably accurate.

Table 2. Density and lattice constants of uranium

\begin{tabular}{|c|c|c|}
\hline $\begin{array}{l}\mathrm{T} \\
{ }^{\circ} \mathrm{C} \\
\end{array}$ & $\begin{array}{c}\text { lattice constants } \\
\mathrm{nm}\end{array}$ & $\begin{array}{l}\text { density } \\
\mathrm{g} / \mathrm{cm}^{3}\end{array}$ \\
\hline$\alpha$-phase & & \\
\hline 25 & $\begin{array}{l}a=0.28545 \\
b=0.58681 \\
c=0.49566\end{array}$ & 19.04 \\
\hline 200 & $\begin{array}{l}a=0.20656 \\
b=0.58653 \\
c=0.49758\end{array}$ & 18.90 \\
\hline 400 & $\begin{array}{l}a=0.28840 \\
b=0.58590 \\
c=0.50041\end{array}$ & 18.70 \\
\hline 650 & $\begin{array}{l}a=0.29196 \\
b=0.58332 \\
c=0.50608\end{array}$ & 18.34 \\
\hline B-phase & & \\
\hline 662 & $\begin{array}{c}a=b=1.0744 \\
c=0.56515\end{array}$ & 18.17 \\
\hline 675 & $\begin{array}{c}a=b=1.0748 \\
c=0.56518\end{array}$ & 18.15 \\
\hline 700 & $\begin{array}{c}a=b=1.0754 \\
c=0.06525\end{array}$ & 18.13 \\
\hline 725 & $\begin{array}{c}a=b=1.0760 \\
c=0.56535\end{array}$ & 18.11 \\
\hline 750 & $\begin{array}{c}a=b=1.0762 \\
c=0.56550\end{array}$ & 18.09 \\
\hline 772 & $\begin{array}{c}a=b=1.0772 \\
c=0.56550\end{array}$ & 18.07 \\
\hline
\end{tabular}

\begin{tabular}{c|c|c}
\hline $\begin{array}{c}\mathrm{T} \\
{ }^{\circ} \mathrm{C}\end{array}$ & $\begin{array}{c}\text { lattice constants } \\
\mathrm{nm}\end{array}$ & $\begin{array}{c}\text { density } \\
\mathrm{g}^{\mathrm{c} \mathrm{cm}^{3}}\end{array}$ \\
\hline$\gamma$-phase & & 17.94 \\
772 & $\mathrm{a}=\mathrm{b}=\mathrm{c}=0.3532$ & 17.91 \\
800 & $\mathrm{a}=\mathrm{b}=\mathrm{c}=0.3534$ & 17.85 \\
850 & $\mathrm{a}=\mathrm{b}=\mathrm{c}=0.3538$ & 17.79 \\
900 & $\mathrm{a}=\mathrm{b}=\mathrm{c}=0.3542$ & 17.73 \\
950 & $\mathrm{a}=\mathrm{b}=\mathrm{c}=0.3546$ & 17.67 \\
1000 & $\mathrm{a}=\mathrm{b}=\mathrm{c}=0.3550$ & 17.62 \\
1050 & $\mathrm{a}=\mathrm{b}=\mathrm{c}=0.3554$ & 17.56 \\
1100 & $\mathrm{a}=\mathrm{b}=\mathrm{c}=0.3557$ & \\
\hline
\end{tabular}




\section{Thermal Expansion}

\section{Liquid}

The thermal expansion of the liquid is directly equivalent to the changes is liquid density.

\section{Solid}

Thermal expansion of solid uranium is complicated by both allotropic phase transformations and crystallographic anisotropy. In general anisotropy can be ignored in fine grain polycrystalline materials. Solidification of a casting, however, usually occurs by nucleation and growth of grains with a preferred crystallographic orientation that is aligned with temperature gradients in the liquid. Therefore, the effect of the crystallographic anisotropy of this physical property should be considered.

Touloukian et al. have surveyed the thermal expansion data in the literature and have developed recommended curves. ${ }^{6}$ The Touloukian data for polycrystalline and single crystal samples appears in Table 3 and Figure 1.

Table 3. Thermal expansion of uranium. The $\alpha \rightarrow \beta$ and $\beta \rightarrow \gamma$ phase transformations occur at 941 and $1048 \mathrm{~K}$ respectively.

\begin{tabular}{c|c|c|c|c|c}
\hline $\begin{array}{c}\text { Temp. } \\
\mathrm{K}\end{array}$ & $\begin{array}{c}/ / \text { a-axis } \\
\Delta L / \%(\%)\end{array}$ & $\begin{array}{c}/ / \mathrm{b} \text {-axis } \\
\Delta \mathrm{L} / \%)\end{array}$ & $\begin{array}{c}/ / \mathrm{c} \text {-axis } \\
\Delta \mathrm{L} / \mathrm{L}(\%)\end{array}$ & $\begin{array}{c}\text { polycryst. } \\
\Delta \mathrm{L} /(\%)\end{array}$ & $\begin{array}{c}\text { polycryst. } \\
\alpha \times 10^{6}\end{array}$ \\
\hline & & & & & \\
200 & -0.210 & -0.006 & -0.170 & -0.128 & 13.4 \\
293 & 0.0 & 0.0000 & 0.0 & 0.0 & 13.9 \\
400 & 0.252 & 0.002 & 0.216 & 0.157 & 15.2 \\
500 & 0.511 & -0.018 & 0.451 & 0.315 & 16.9 \\
600 & 0.807 & -0.063 & 0.737 & 0.494 & 19.0 \\
700 & 1.161 & -0.162 & 1.09 & 0.697 & 21.4 \\
800 & 1.587 & -0.305 & 1.49 & 0.924 & 24.3 \\
900 & 2.104 & -0.452 & 1.907 & 1.186 & 27.7 \\
941 & 2.346 & -0.527 & 2.076 & 1.300 & 29.1 \\
941 & & & & 1.635 & 17.3 \\
1000 & & & & 1.737 & 17.3 \\
1048 & & & & 1.820 & 17.3 \\
1048 & & & & 2.050 & 22.9 \\
1100 & & & & 2.168 & 22.9 \\
1200 & & & & 2.398 & 22.9 \\
1400 & & & & 2.855 & 22.7 \\
\hline
\end{tabular}




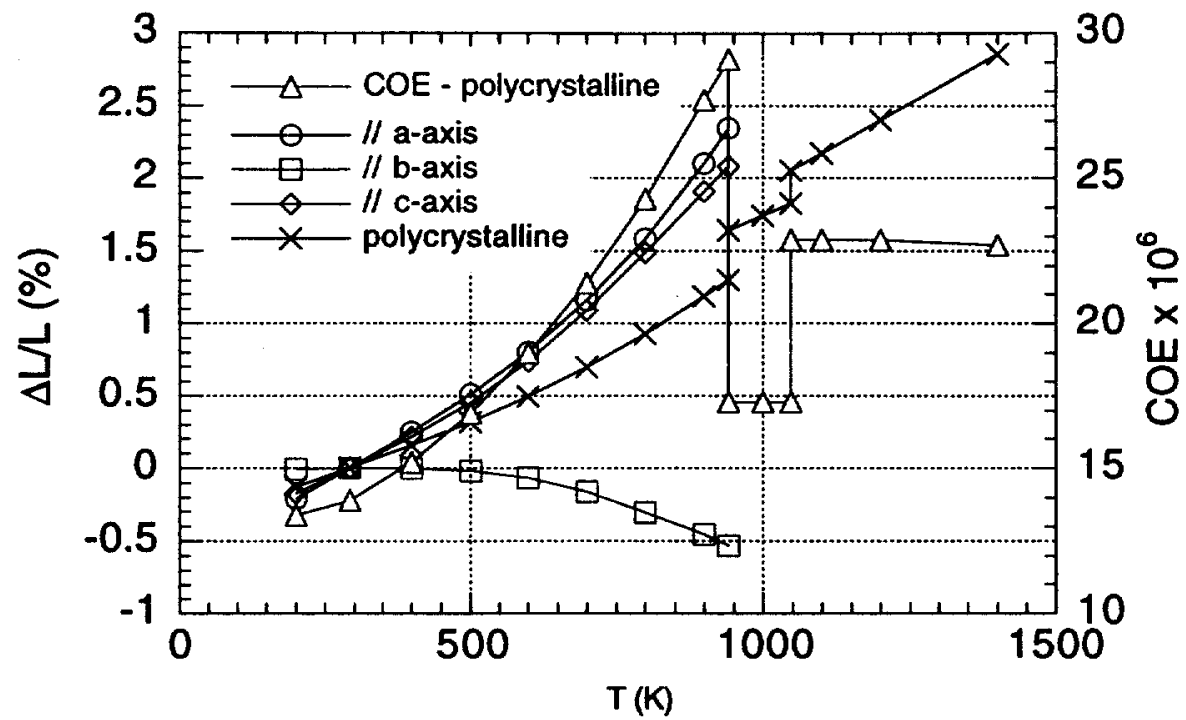

Figure 1. Thermal expansion of uranium.

\section{Thermal Conductivity}

\section{Liquid Phase}

There is no readily available data on thermal conductivity of liquid uranium. This is in part due to the experimental difficulty of measuring conductivity at high temperatures and also to the high reactivity of molten $U$ with mold materials.

It is possible, with a small leap of faith, to use electrical resistivity data and the WiedmannFranz-Lorentz law to predict the thermal conductivity. The WFL law is well established for solids and has been demonstrated to hold for molten, low-melting point metals. Electrical resistivity data exists for liquid U; however, the validity of the WFL law to liquid U has not been demonstrated due to the lack of direct thermal conductivity measurements.

The WFL law simply states that the resistivity is proportional to the thermal conductivity. The relation is given as,

$$
\frac{\lambda \rho}{T}=\frac{\pi^{2} k^{2}}{3 e^{2}}=2.45 \times 10^{-8}\left(W \Omega K^{-2}\right)
$$

where,

$\lambda=$ thermal conductivity

$\rho=$ electrical resistivity

$k=$ Boltzmann's constant

$\mathrm{e}=$ electric charge

There have been several experiments to evaluate the high temperature electrical properties of liquid uranium. Gathers et al. used the isobaric expansion method to determine the equation of state of liquid uranium to very high temperatures and pressures. ${ }^{7}$ The isobaric expansion 
experiment also provides a means to directly measure the electrical resistivity of the liquid. Gathers' data has been replotted and is shown in Figure 2. In his paper Gathers shows evidence that the data from isobaric expansion experiment (a dynamic measurement) is comparable to data obtained from solid uranium using static techniques.

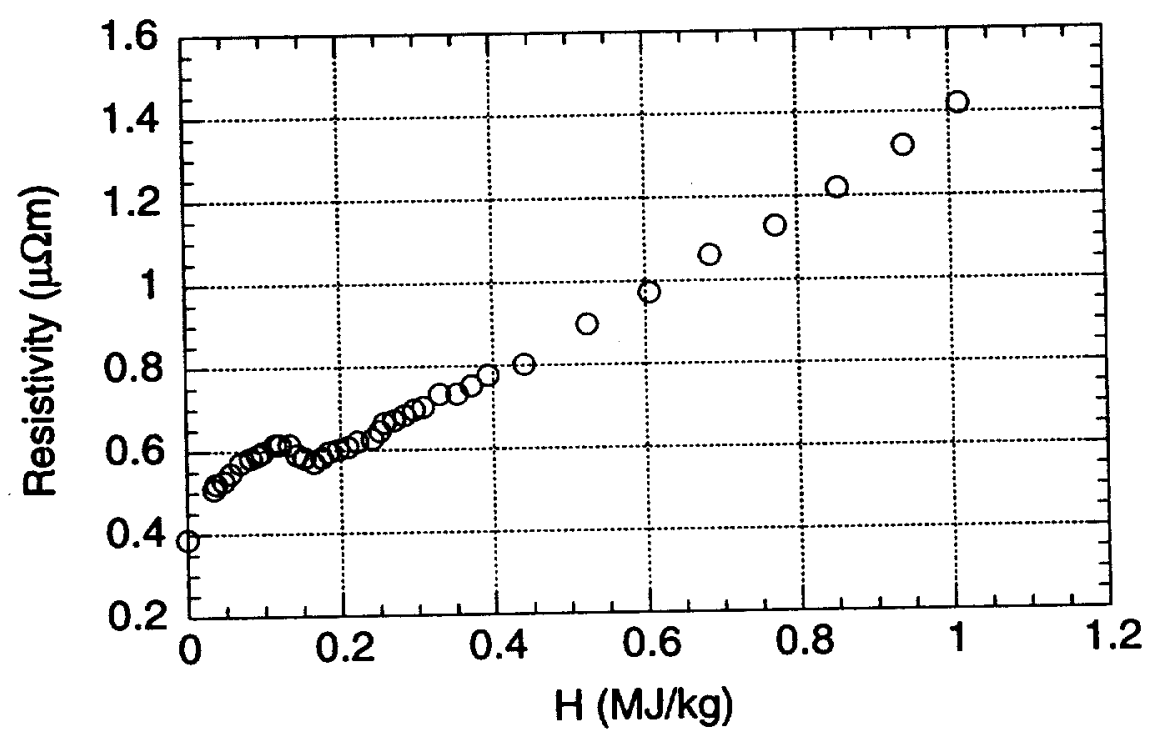

Figure 2. The resistivity of uranium as a function of enthalpy. The discontinuity observed below 0.2 $\mathrm{MJ} / \mathrm{kg}$ results from the polymorphic phase changes and melting.

Mulford and Sheldon performed similar experiments and show a linear correlation between uranium enthalpy and its temperature. ${ }^{8} \mathrm{~A}$ best fit to their data, replotted in Figure 3, is $H(\mathrm{~kJ} / \mathrm{mol})=-9.793+0.04272 T(K)$.

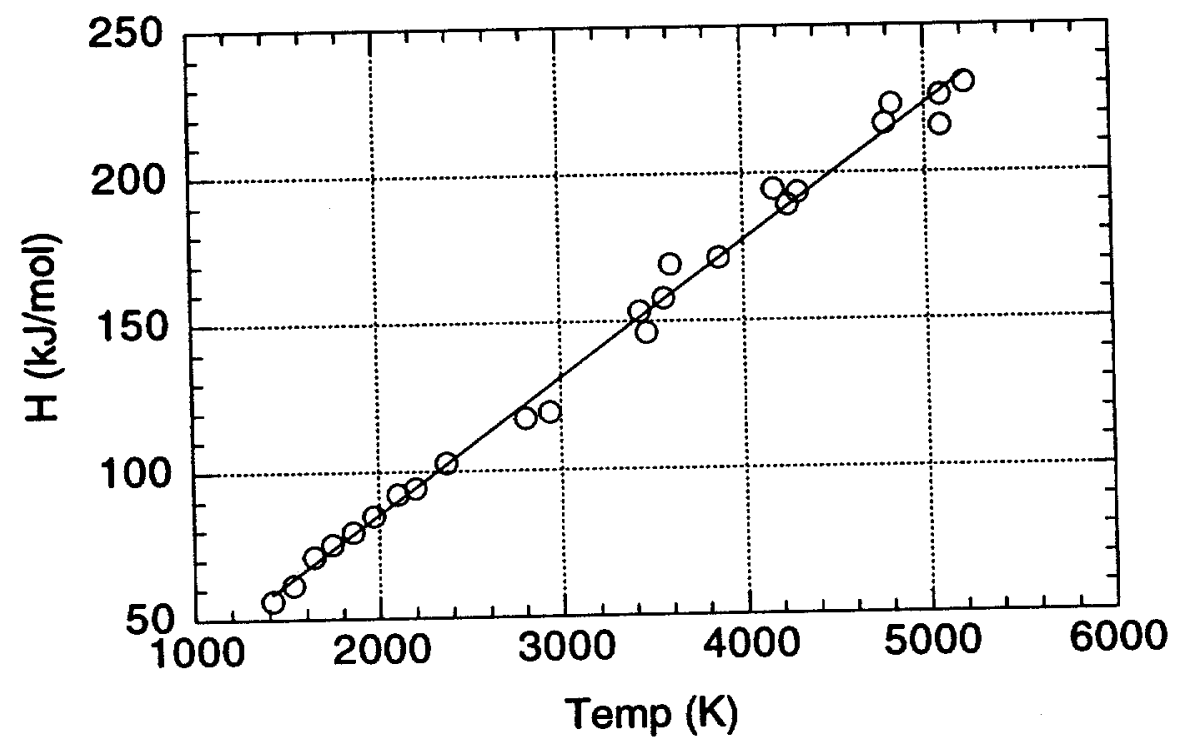

Figure 3. The temperature of uranium as a function of enthalpy (isobaric). 
Using the data of Gathers et al., Mulford et al., and the Wiedmann-Franz-Lorentz law we can calculate the thermal conductivity of uranium at high temperatures. The results are shown in Table 3 and in Figure 4. A best fit curve is provided for use in calculation.

Table 3. The transport properties of liquid uranium. The resistivity and enthalpy data are from Gathers et al., and Mulford et al. ${ }^{7,8}$ The thermal conductivity was calculated using the Wiedmann-Franz-Lorentz law.

\begin{tabular}{c|c|c|c}
\hline Temperature & Enthalpy & Resistivity & $\begin{array}{c}\text { Thermal } \\
\text { conductivity } \\
\text { W/(m・K) }\end{array}$ \\
\hline $\mathrm{K}$ & $\mathrm{kJ} / \mathrm{mol}$ & $\boldsymbol{\mu} \cdot \mathrm{m}$ & \\
1405 & 56.52 & 0.64 & 53.46 \\
1425 & 57.47 & 0.65 & 53.94 \\
1450 & 58.65 & 0.65 & 54.53 \\
1475 & 59.83 & 0.66 & 55.11 \\
1500 & 61.01 & 0.66 & 55.69 \\
1525 & 62.19 & 0.66 & 56.26 \\
1550 & 63.37 & 0.67 & 56.82 \\
1575 & 64.55 & 0.67 & 57.38 \\
1600 & 65.73 & 0.68 & 57.93 \\
1625 & 66.91 & 0.68 & 58.47 \\
1650 & 68.09 & 0.69 & 59.00 \\
1675 & 69.27 & 0.69 & 59.53 \\
1700 & 70.45 & 0.69 & 60.05 \\
1725 & 71.63 & 0.70 & 60.57 \\
1750 & 72.81 & 0.70 & 61.08 \\
1775 & 73.99 & 0.71 & 61.58 \\
1800 & 75.17 & 0.71 & 62.08 \\
1825 & 76.35 & 0.71 & 62.57 \\
1850 & 77.53 & 0.72 & 63.06 \\
1875 & 78.71 & 0.72 & 63.54 \\
1900 & 79.89 & 0.73 & 64.02 \\
1925 & 81.07 & 0.73 & 64.49 \\
1950 & 82.25 & 0.74 & 64.95 \\
1975 & 83.43 & 0.74 & 65.41 \\
2000 & 84.61 & 0.74 & 65.86 \\
\hline & & &
\end{tabular}




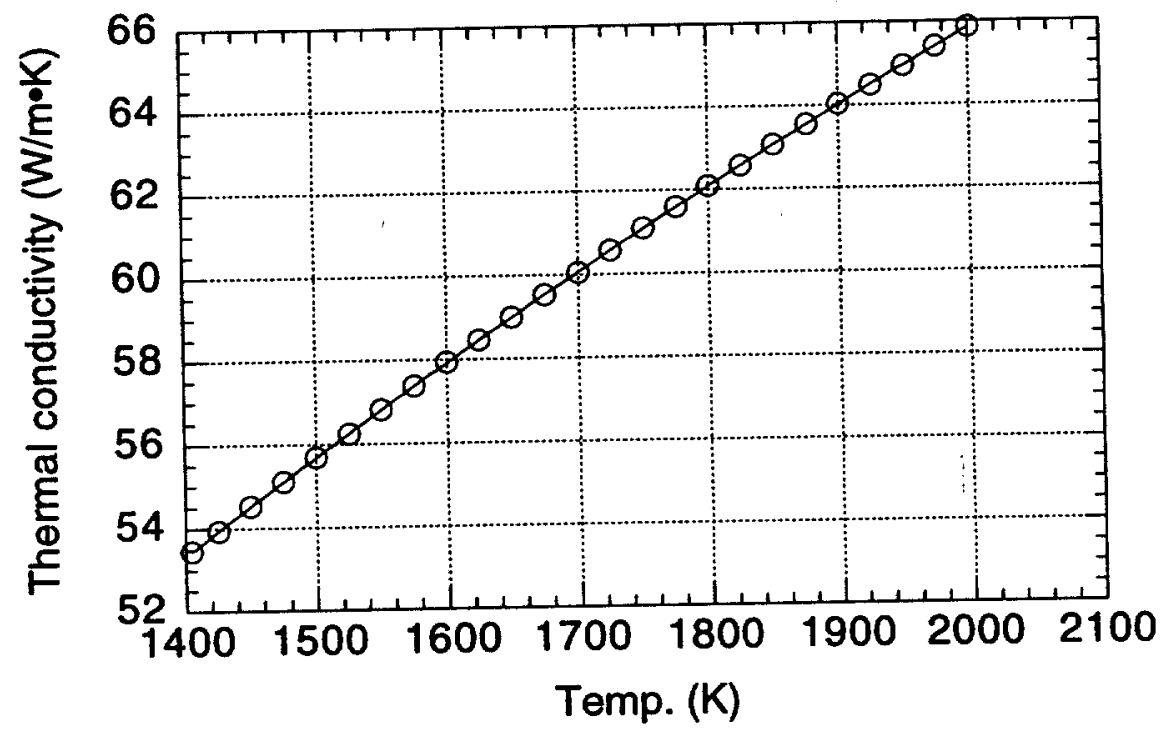

Figure 4. The thermal conductivity of liquid uranium as a function of temperature. A best fit to the data is obtained using the 2 nd order polynomial expression $\alpha(W / m \cdot K)=10.154+0.03787 T-5.0103 \times 10^{-6} T^{2}$.

\section{Solid phase}

The thermal conductivity of solid uranium has been well studied by a number of researchers and a good summary and analysis of the data appears in Touloukian et al. 9 Table 4 and Figure 5 shows the Touloukian et al's. recommended curve for annealed high purity polycrystalline uranium ( $>99.5 \mathrm{wt}$. \% purity).

Table 4. The thermal conductivity of uranium as a function of temperature.

\begin{tabular}{c|c}
\hline Temperature & $\begin{array}{c}\text { Thermal } \\
\text { conductivity } \\
\text { W cm } \mathrm{K}^{-1}\end{array}$ \\
$\mathrm{~K}$ & \\
250 & 0.264 \\
273.2 & 0.270 \\
300 & 0.276 \\
350 & 0.286 \\
400 & 0.296 \\
500 & 0.317 \\
600 & 0.340 \\
700 & 0.364 \\
800 & 0.388 \\
900 & 0.413 \\
1000 & 0.439 \\
1100 & 0.463 \\
1200 & 0.490 \\
\hline
\end{tabular}




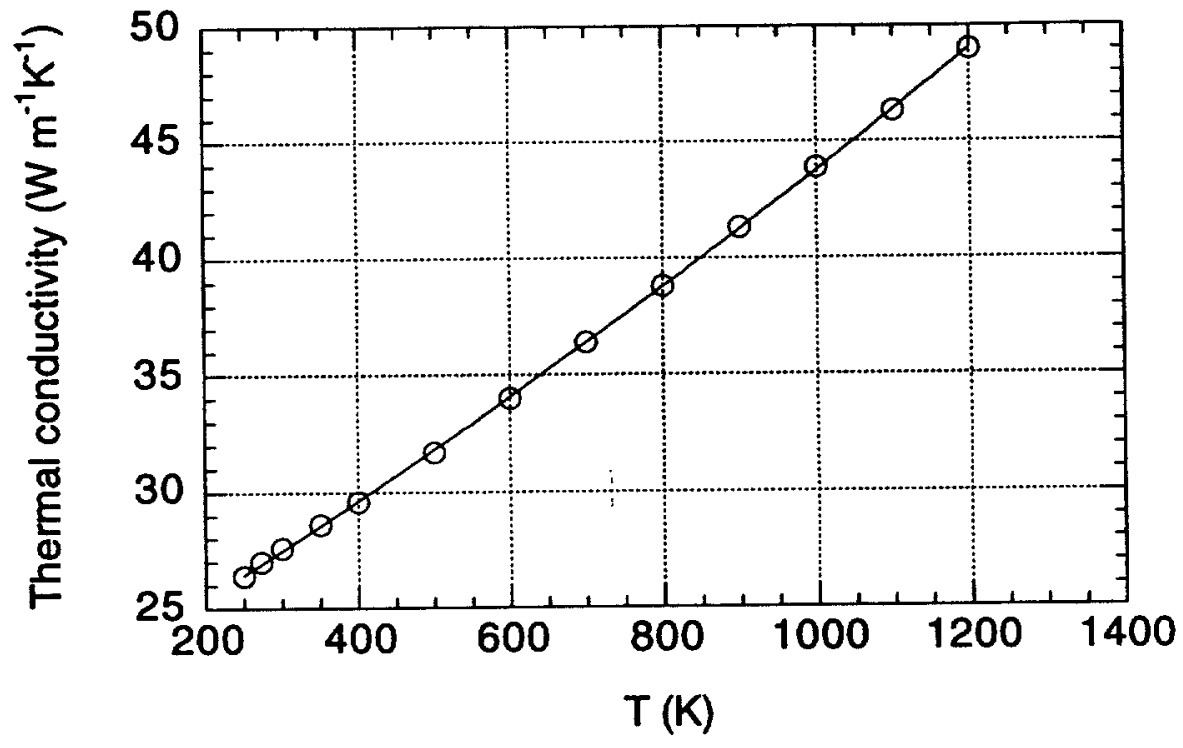

Figure 5. The thermal conductivity of solid uranium as a function of temperature. A good fit to the data was obtained using the second order polynomial expression $\alpha=21.559+1.8801 \times 10^{-2} T+3.4144 \times 10^{-6} T^{2}$

\section{Heat Capacity}

\section{Liquid}

The heat capacity of the liquid, as reported by Mulford et al., is linear with respect to temperature and has a value of $0.0472 \mathrm{~kJ} \mathrm{~mol}^{-1} \mathrm{~K}^{-1}\left(11.3 \mathrm{cal} \mathrm{mol}^{-1} \mathrm{~K}^{-1}\right) .8$ This is similar to the value of $11.6 \mathrm{cal} \mathrm{mol}^{-1} \mathrm{~K}^{-1}$ reported by Stephens using a calorimetric technique. 8

\section{Solid}

A good review of specific heat data of solid uranium is reported by Touloukian and Buyco. 10 The data from the sources cited by Touloukian and Buyco are shown in Figure 6 and Table 5. There is good agreement among all the sources with the exception of the data for curve 4 in the $\beta$ and $\gamma$ regions. It is recommended that the data in curve 4 be discounted. 


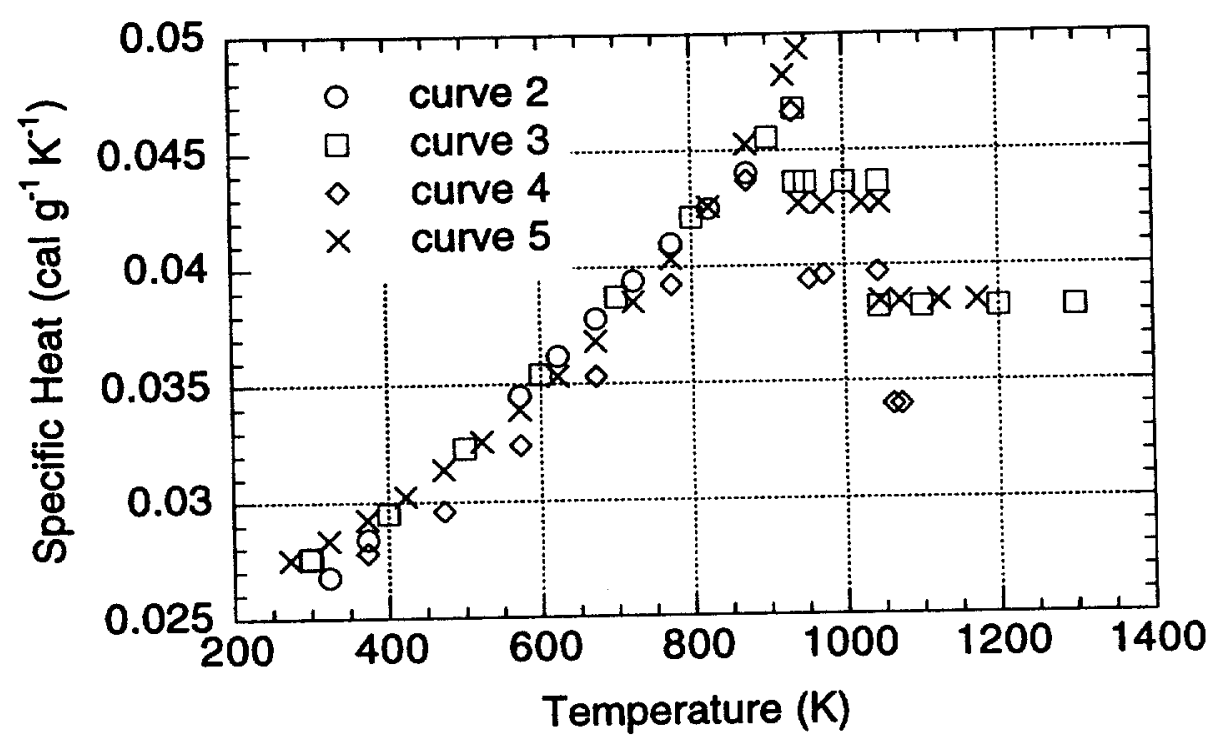

Figure 6. The specific heat of solid uranium. The curve numbers refer to the order in which Touloukian and Buyco reference the data sources.

Table 5. The specific heat of solid uranium.

\begin{tabular}{|c|c|c|c|c|c|c|c|}
\hline $\begin{array}{r}\text { Temp. } \\
\mathbf{K} \\
\mathrm{c} \\
\end{array}$ & $\begin{array}{l}\text { Spec. Heat } \\
\text { cal } \mathrm{g}^{-1} \mathrm{~K}^{-1} \\
\text { ve } 2\end{array}$ & $\begin{array}{c}\text { Temp. } \\
\mathbf{K} \\
\end{array}$ & 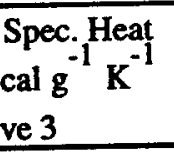 & $\begin{array}{c}\text { Temp. } \\
\mathrm{K} \\
\end{array}$ & $\begin{array}{l}\text { Spec. Heat } \\
\text { cal }^{-1} \mathrm{~K}^{-1} \\
\text { ve } 4\end{array}$ & $\begin{array}{c}\text { Temp. } \\
\mathbf{K} \\
\end{array}$ & 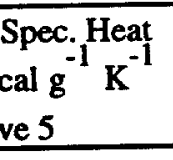 \\
\hline $\begin{array}{l}323.15 \\
373.15 \\
573.15 \\
623.15 \\
673.15 \\
723.15 \\
773.15 \\
823.15 \\
873.15\end{array}$ & $\begin{array}{l}0.026800 \\
0.028400 \\
0.034500 \\
0.036200 \\
0.037800 \\
0.039400 \\
0.041000 \\
0.042500 \\
0.044000\end{array}$ & $\begin{array}{l}298.00 \\
300.00 \\
400.00 \\
500.00 \\
600.00 \\
700.00 \\
800.00 \\
900.00 \\
935.00 \\
935.00 \\
950.00 \\
1000.0 \\
1045.0 \\
1045.0 \\
1100.0 \\
1200.0 \\
1300.0\end{array}$ & $\begin{array}{l}0.027580 \\
0.027600 \\
0.029510 \\
0.032300 \\
0.035430 \\
0.038730 \\
0.042120 \\
0.045550 \\
0.046760 \\
0.043600 \\
0.043600 \\
0.043600 \\
0.043600 \\
0.038220 \\
0.038220 \\
0.038220 \\
0.038220\end{array}$ & $\begin{array}{l}373.15 \\
473.15 \\
573.15 \\
673.15 \\
773.15 \\
873.15 \\
933.15 \\
953.15 \\
973.15 \\
1043.2 \\
1063.2 \\
1073.2\end{array}$ & $\begin{array}{l}0.027800 \\
0.029600 \\
0.032400 \\
0.035300 \\
0.039200 \\
0.043700 \\
0.046600 \\
0.039400 \\
0.039600 \\
0.039700 \\
0.034000 \\
0.034000\end{array}$ & $\begin{array}{l}273.15 \\
323.15 \\
373.15 \\
423.15 \\
473.15 \\
523.15 \\
573.15 \\
623.15 \\
673.15 \\
723.15 \\
773.15 \\
823.15 \\
873.15 \\
923.15 \\
941.15 \\
941.15 \\
973.15 \\
1023.2 \\
1047.2 \\
1047.2 \\
1073.2 \\
1123.2 \\
1173.2\end{array}$ & $\begin{array}{l}0.027500 \\
0.028300 \\
0.029190 \\
0.030220 \\
0.031350 \\
0.032570 \\
0.033880 \\
0.035290 \\
0.036810 \\
0.038460 \\
0.040310 \\
0.042530 \\
0.045210 \\
0.048180 \\
0.049300 \\
0.042620 \\
0.042620 \\
0.042620 \\
0.042620 \\
0.038430 \\
0.038430 \\
0.038430 \\
0.038430 \\
\end{array}$ \\
\hline
\end{tabular}


References for Appendix 2 only.

1. William D. Drotning, "Density and Thermal Expansion of Liquid U-Nb Alloys," High Temperatures - High Pressures 14, 253-258 (1982).

2. J.W. Shaner, "Thermal Expansion of Metals Over the Entire Liquid Range," in Thermal Expansion, edited by Ian D. Peggs (Plenum Publishing Company, New York, 1978), Vol. 6, pp. 69-81.

3. A.V. Grosse, J.A. Cahill, and A.D. Kishenbaum, Journal of the American Chemical Society 83, 4665 (1961).

4. Takamishi Iida and Roderick I.M. Guthrie, The Physical Properties of Metals (Oxford University Press, Oxford, 1988).

5. J.H. Gittus, Uranium (Butterworths, Washington, 1963).

6. Y.S. Touloukian, R.K. Kirby, R.E. Taylor et al., Thermal Expansion Metallic Elements and Alloys (IFI/Plenum Data Company, New York, 1975).

7. G.R. Gathers, J.W. Shaner, and D.A. Young, "Experimental, Very HighTemperature, Liquid-Uranium Equation of State," Physical Review Letters 33 (2), 70-72 (1974).

8. R.N.R. Mulford and R.I. Sheldon, "Density and Heat Capacity of Liquid Uranium at High Temperatures," Journal of Nuclear Materials 154, 268-275 (1988).

9. Y.S. Touloukian, R.W. Powell, C.Y. Ho et al., Thermal Conductivity - Metallic Elements and Alloys (IFI/Plenum Data Company, New York, 1970).

10. Y.S. Touloukian and E.H. Buyco, Specific Heat - Metallic Elements and Alloys (IFI/Plenum Data Company, New York, 1970). 


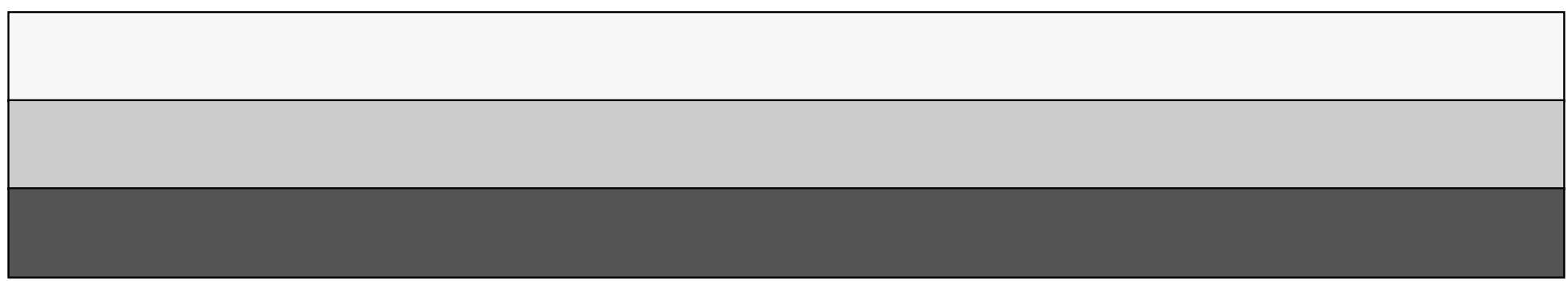

